\title{
SISTEM INFORMASI DATA PENDUDUK DENGAN MENGGUNAKAN DATABASE TERDISITRIBUSI
}

\author{
Muhazzir $^{1)}$ dan Sriwinar ${ }^{2)}$ \\ ${ }^{1)}$ Mahasiswa Program Studi Informatika, Fakultas Ilmu Komputer, Universitas Almuslim Bireuen \\ 2) Dosen Program Studi Informatika Fakultas Ilmu Komputer Universitas Almuslim Bireuen \\ e-mail: muhaz.zir1234@gmail.com
}

\begin{abstract}
[Population Data Information System using Distributed Database] Population data is something that must be managed by the government to be processed to various needs, both regional and central. The existence of data is also required to be always up to date (current). The management of population data in the village of juli uruek anoe, juli sub-district, Bireuen district, is still processed manually by the village structural government, for example population data or population movement data managed by the village secretary, while birth data is managed by village midwives and then sent to the village population data manager. With the concept of a distributed database, a system can be built which is directly managed by the village midwife when a resident gives birth to be stored or input into the system. The system image describes the data flow in general, namely there are 4 entities in the designed application, including the system admin to input and manage user application users, then sub-district operators and district operators can view the report data, then village secretary users to input family card data , population data, mortality data, displacement data, arrival data.
\end{abstract}

Keywords: Bireuen; MySQL; Population; PHP.

\begin{abstract}
Abstrak
Data kependudukan merupakan suatu hal yang harus dikelola baik oleh pemerintah untuk diolah sampai pada berbagai keperluan, baik daerah maupun pusat. Keberadaan datanya pun dituntut untuk selalu up to date (saat ini). Pengelolaan data penduduk di desa juli uruek anoe kecamatan juli kabupaten Bireuen masih diolah secara manual oleh pemerintah struktural desa, misalnya data penduduk atau data perpindahan penduduk yang dikelola oleh sekretaris desa, sementara data kelahiran dikelola oleh bidan desa kemudian dikirim kepada pengelola data penduduk di desa. Dengan konsep database terdistribusi dapat dibangun sebuah sistem yang langsung dikelola oleh bidan desa ketika ada penduduk yang melahirkan untuk disimpan atau diinput kedalam sistem. Gambar sistem menjelaskan aliran data secara umum, yaitu terdapat 4 entitas pada aplikasi yang di rancang, di antaranya admin sistem untuk menginput dan mengelola user pengguna aplikasi, kemudian operator kecamatan dan operator kabupaten dapat melihat data laporan, kemudian pengguna sekretaris desa untuk menginput data kartu keluarga, data penduduk, data kematian, data pindahan, data kedatangan.
\end{abstract}

Kata Kunci: Bireuen; Penduduk; MySQL; PHP.

\section{Pendahuluan}

Data kependudukan merupakan suatu hal yang harus dikelola baik oleh pemerintah untuk diolah sampai pada berbagai keperluan, baik daerah maupun pusat (Ibrahim, Rifai, \& Oktarina, 2016; Rusdiana, 2018). Keberadaan datanya pun dituntut untuk selalu up to date (saat ini) (Alda, 2020; Hastuti, 2020). Pengelolaan data penduduk di desa Juli Uruek Anoe Kecamatan Juli Kabupaten Bireuen masih diolah secara manual oleh pemerintah struktural desa, misalnya data penduduk atau data perpindahan penduduk yang dikelola oleh sekretaris desa, sementara data kelahiran dikelola oleh bidan desa kemudian dikirim kepada pengelola data penduduk di desa. Kendala yang dialami pada saat ini adalah pada tingkat efisien waktu kerja, bidan desa harus membuat rekap data kelahiran untuk diserahkan kepada sekretaris desa untuk kemudian diolah pada keperluan administrasi data penduduk di desa, proses seperti ini memakan waktu kerja yang lama dan kinerja yang sulit 
karena terkadang bidan melayani banyak orang melahirkan di desa, pada dasarnya proses-proses ini dapat dinormalisasikan dengan peran teknologi komputer dan jaringan internet (Josi, 2017; Sofiyudin \& Nugroho, 2017; Sundari \& Nainggolan, 2017). Dengan konsep database terdistribusi dapat dibangun sebuah sistem yang langsung dikelola oleh bidan desa ketika ada penduduk yang melahirkan untuk disimpan atau diinput kedalam sistem (Rosyidah, 2016; Utomo, Astuti, \& Setyawan, 2020), kemudian data yang penduduk yang melahirkan dapat langsung dikirim kepada sekretaris desa melalui sistem database untuk diakses secara bersamaan oleh sekretaris desa dan bidan desa (Astuti, Dharmawan, Mawarni, \& Nugroho, 2020; Kusuma, Shodiq, Yusuf, \& Saadah, 2019). proses komputerisasi menggunakan konsep database terdistribusi ini dapat menjadi solusi dalam meningkatkan kecapatan waktu kerja bidan desa dan sekretaris desa dalam mengelola data penduduk (Cinderatama, Yuwono, \& Asmara, 2011; Dharmasurya, Wahyono, \& Somya, 2013; Sutanta \& Ashari, 2012).

\section{Metode}

A. Metode Penelitian

Adapun metode yang digunakan dalam penelitian ini adalah sebagai berikut:

1. Observasi (Pengamatan), penyusun melakukan pengamatan secara langsung untuk memperoleh informasi tentang prosedur yang berlaku dalam pelaksanaan sistem yang sedang berjalan.

2. Interview (Wawancara), pada tahap ini penulis mengumpulkan data penelitian dengan teknik pengumpulan data yang dilakukan melalui proses tanya jawab dengan pihak-pihak yang terkait langsung dengan obyek penelitian.

3. Library Research (Studi Kepustakaan), yaitu metode penulisan yang dilakukan dengan melakukan studi kepustakaan pada perpustakaan Universitas Almuslim.

\section{B. Perancangan Sistem}

Tujuan dari perancangan sistem adalah untuk memenuhi kebutuhan user (pemakai) mengenai gambaran yang jelas tentang perancangan sistem yang akan dibuat serta diimplementasikan. Perancangan sistem adalah suatu upaya untuk membuat suatu sistem yang baru atau memperbaiki sistem yang lama secara keseluruhan atau memperbaiki sistem yang telah ada. Desain sistem secara umum mengidentifikasikan komponen-komponen sistem informasi yang akan didesain secara terinci. Desain terinci dimaksudkan untuk pemrogram komputer dan ahli teknik lainnya yang akan mengimplementasikan sistem.

1. Perancangan Diagram Konteks

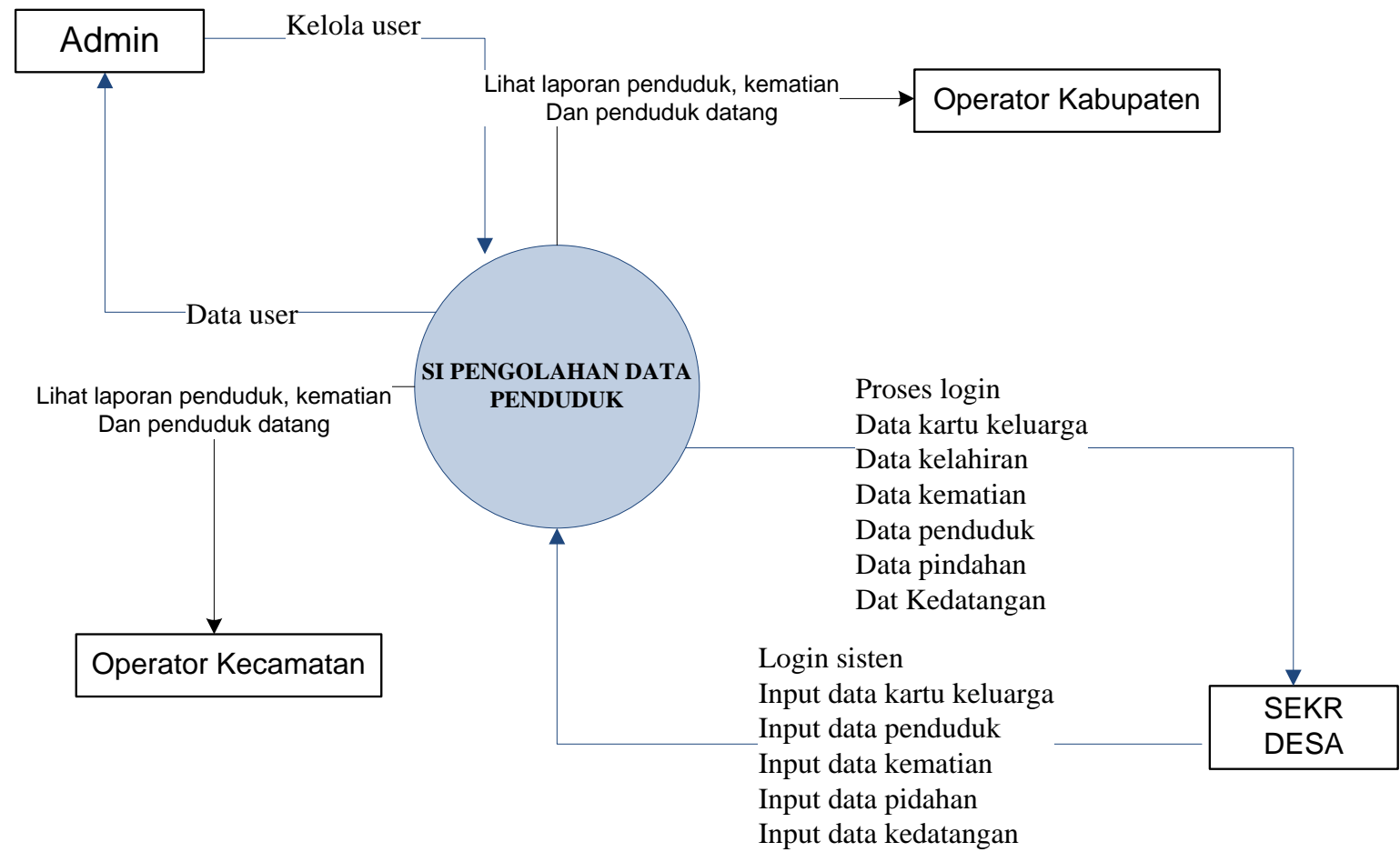

Gambar 1. Contex Diagram

Gambar diatas menjelaskan aliran data secara umum, yaitu terdapat 4 entitas pada aplikasi yang di rancang, di antaranya admin sistem untuk menginput dan mengelola user pengguna aplikasi, kemudian operator 
kecamatan dan operator kabupaten dapat melihat data laporan, kemudian pengguna sekretaris desa untuk menginput data kartu keluarga, data penduduk, data kematian, data pindahan, data kedatangan.

2. Perancangan Basis Data

Basis Data merupakan kumpulan dari data-data yang saling terkait dan berhubungan satu sama lain. Perancangan basis data merupakan perancangan yang digunakan untuk pembuatan dan penyimpanan data kedalam sistem terdiri dari beberapa file database. Pada perancangan basis data ini akan dibahas Normalisasi, Entity Relationship Diagram (ERD) dan Struktur File.

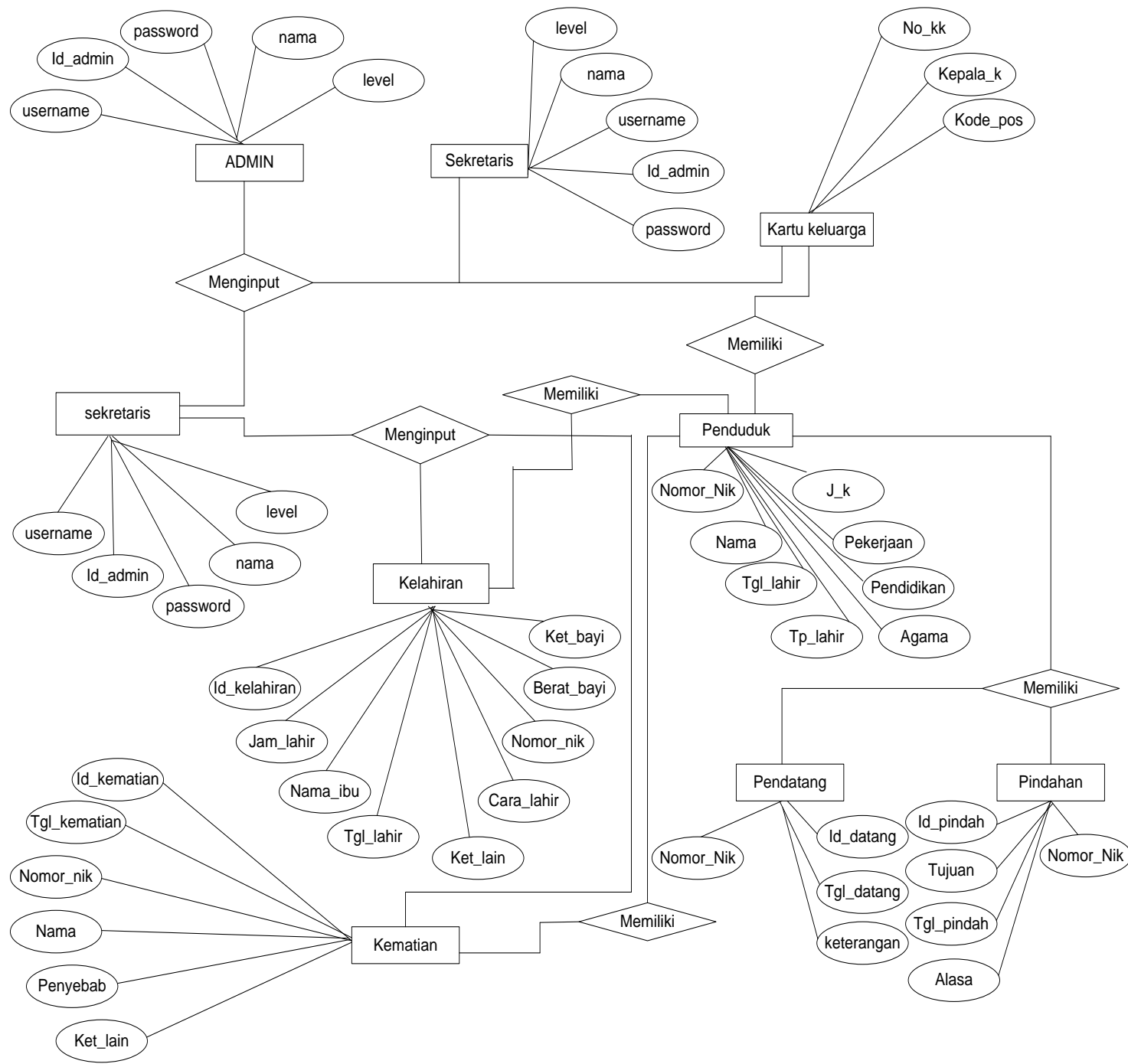

Gambar 2. Entity Relationship Diagram (ERD)

3. Rancangan User Interface

a) Form Login

Untuk dapat melakukan proses yang lengkap pada sistem, user diharuskan melakukan proses login terlebih dahulu. Proses login dapat dilakukan jika user sudah memiliki username dan password. Desain fungsi login seperti berikut: 
Username

\begin{tabular}{|l|l|}
\hline \\
\hline
\end{tabular}

Password

\section{Login}

b) Halaman Input User

Gambar 3. Form Login

Gambar berikut merupakan halaman input user digunakan oleh user level administrator untuk menginput datadata pengguna aplikasi level user bidan, dan sekretaris.

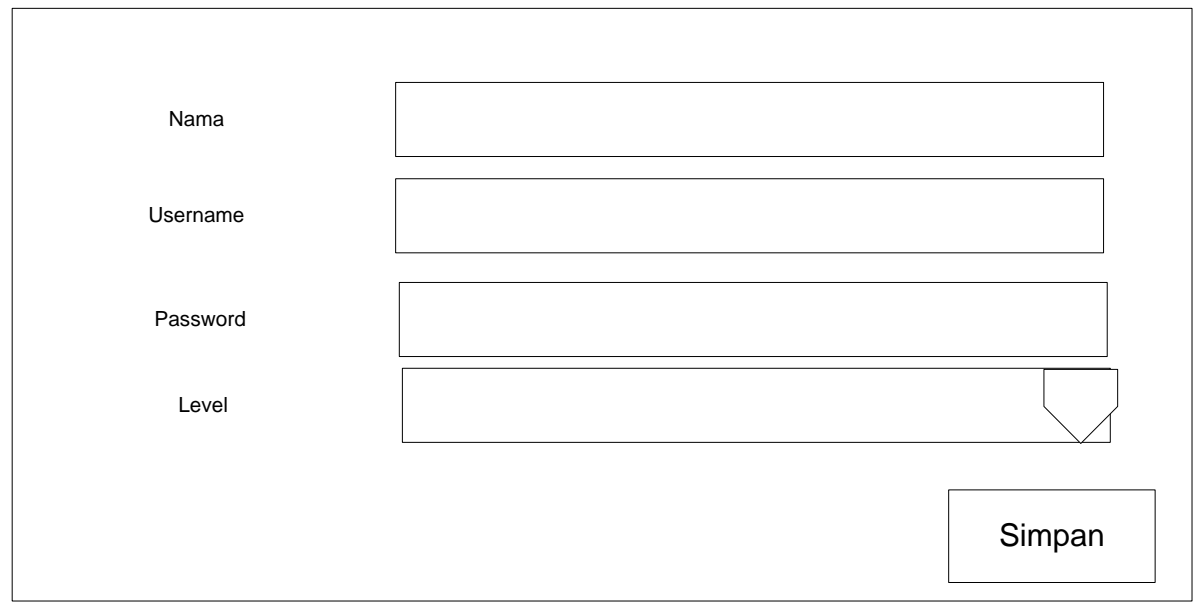

Gambar 4. Halaman Input User

c) Halaman Input Kartu Keluarga

Berikut perancangan halaman input kartu keluarga untuk user.

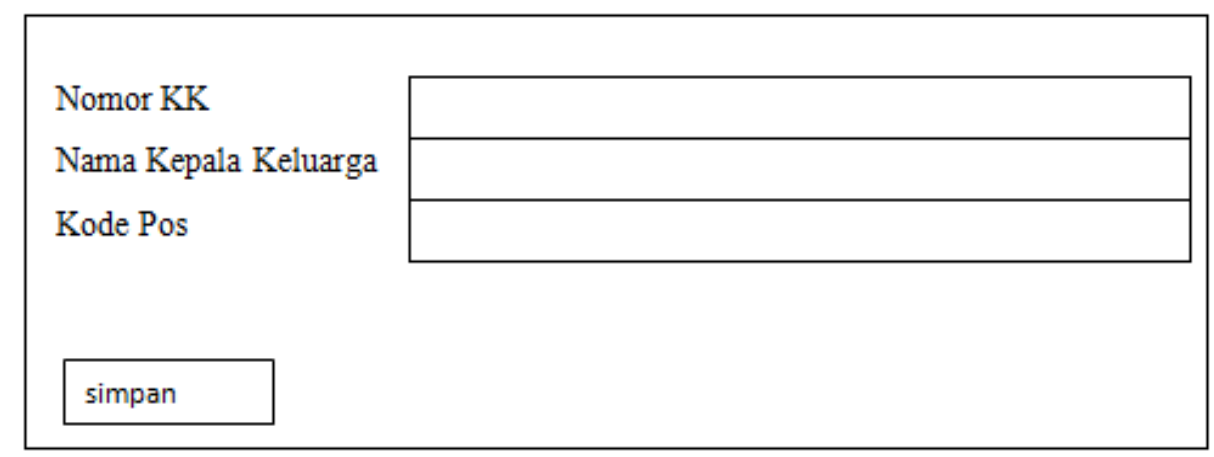

Gambar 5. Halaman Input Kartu Keluarga.

\section{Hasil dan Pembahasan}

Pengujian merupakan bagian yang penting dalam siklus pembangunan perangkat lunak. Pengujian dilakukan untuk menjamin kualitas dan juga mengetahui kelemahan dari perangkat lunak. Tujuan dari pengujian ini adalah untuk menjamin bahwa perangkat lunak yang dibangun memiliki kualitas yang handal.

1. Halaman Login 

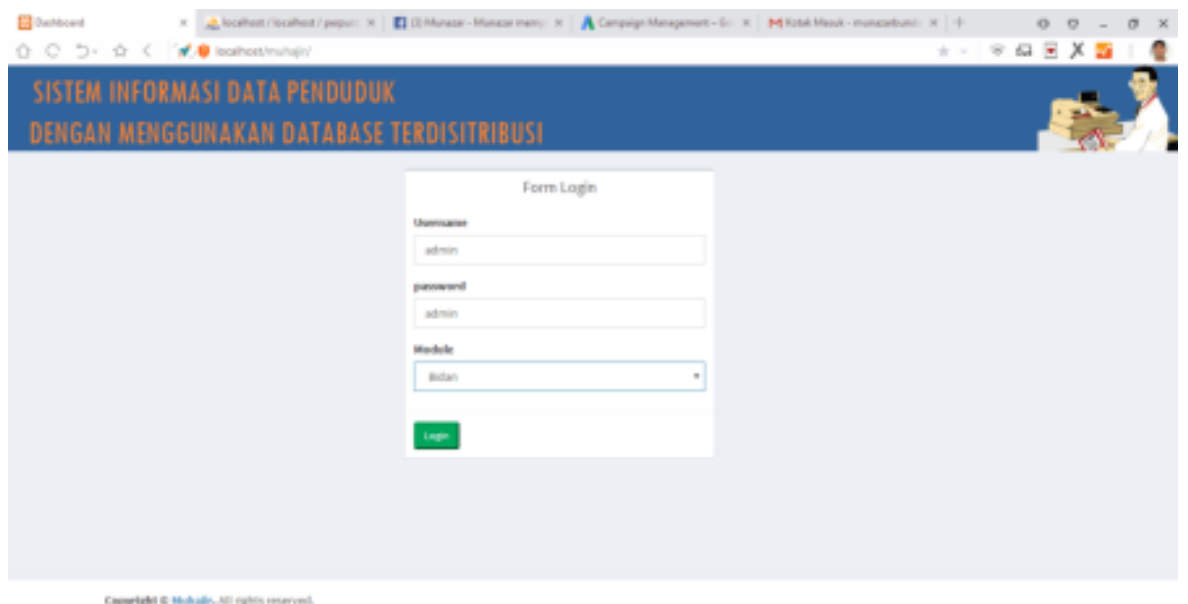

2. Halaman Input User

Gambar 6. Halaman Login

Tampilan menu input user pada sistem informasi data penduduk terdistribusi:

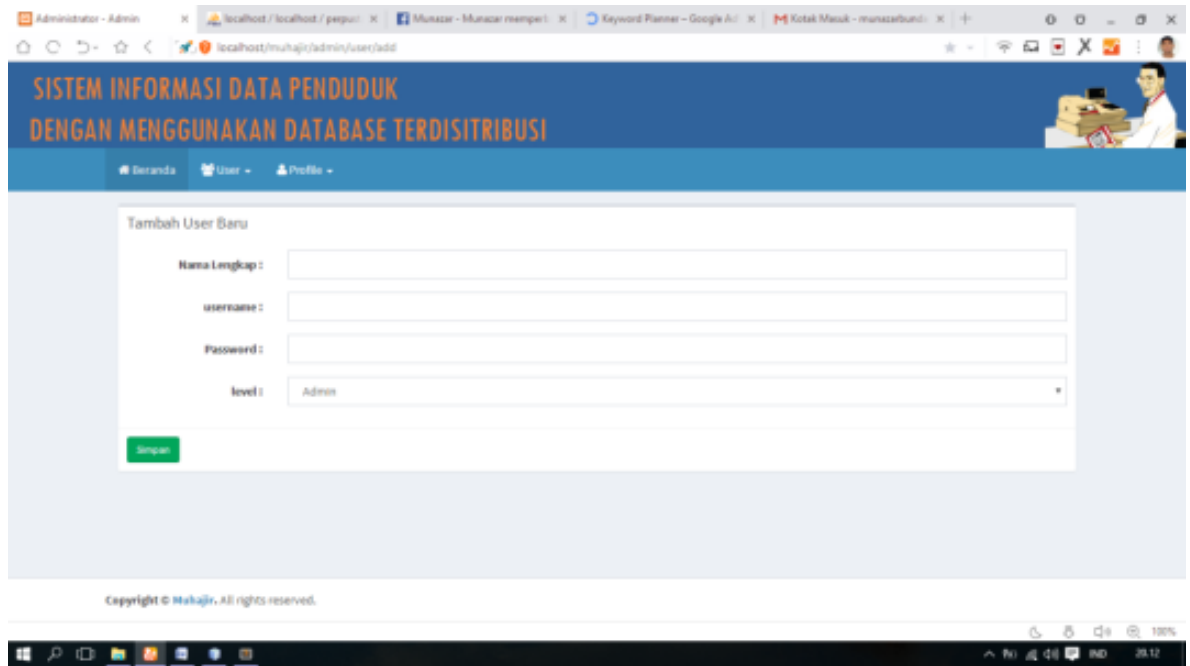

Gambar 7. Halaman Input User

3. Halaman Input Kartu Keluarga

Tampilan menu input kartu keluarga pada sistem informasi data penduduk terdistribusi:

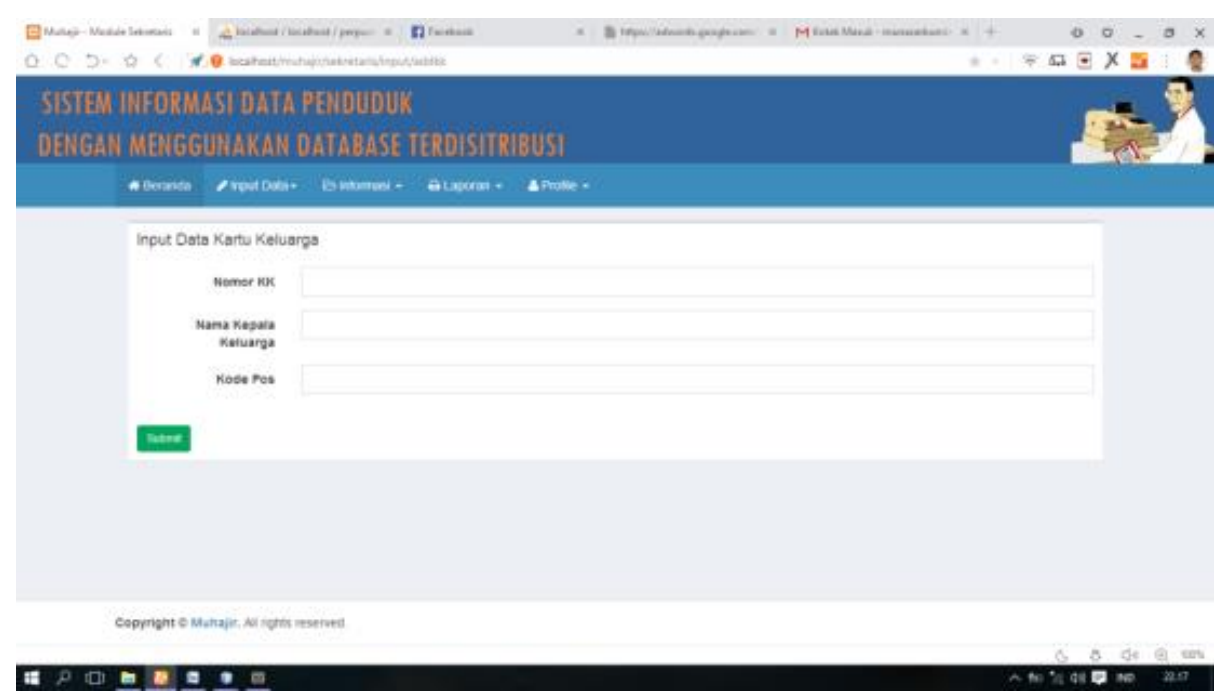

Gambar 8. Halaman Input Kartu Keluarga 


\section{Kesimpulan}

Berdasarkan hasil penelitian yang dilakukan penulis pada proses penyusunan tugas akhir dapat disimpulkan beberapa kesimpulan yaitu :

1) Telah berhasil dibuat Sistem Informasi data penduduk menggunkan database terdistribusi.

2) Sistem informasi data penduduk terdiri dari tiga level pengguna yaitu, pengguna admin, sekretaris dan level bidan.

3) Hasil akhir laporan dari proses data ini beberapa laporan diantaranya laporan data penduduk, laporan kelahiran, laporan data penduduk pendatang, laporan penduduk kematian.

\section{Daftar Pustaka}

Alda, M. (2020). Sistem Informasi Pengolahan Data Kependudukan Pada Kantor Desa Sampean Berbasis Android. JURNAL MEDIA INFORMATIKA BUDIDARMA, 4(1), 1-8.

Astuti, B. D., Dharmawan, Y., Mawarni, A., \& Nugroho, R. D. (2020). PENGEMBANGAN SISTEM INFORMASI DESA SIAGA (STUDI KASUS PADA DESA SIAGA AKTIF SUKODONO TAHUN 2019). Jurnal Kesehatan Masyarakat (e-Journal), 8(2), 89-99.

Cinderatama, T. A., Yuwono, W., \& Asmara, R. (2011). Basis Data Terdistribusi untuk Aplikasi Kependudukan Berbasis Web. EEPIS Final Project.

Dharmasurya, A., Wahyono, T., \& Somya, R. (2013). Pengembangan Sistem Terdistribusi Untuk Sistem Informasi Administrasi Kependudukan Dengan Integrasi Teknologi RMI dan Web Service. Jurnal Teknologi Informasi-Aiti, 10(1), 1-100.

Hastuti, S. H. D. (2020). Pentingnya Pemanfaatan Data Kependudukan Di Era Digital. TEKNIMEDIA: Teknologi Informasi Dan Multimedia, 1(1), 18-21.

Ibrahim, A., Rifai, A., \& Oktarina, L. (2016). Rancang Bangun Aplikasi Pencatatan Data Kependudukan Kelurahan Pahlawan Berbasis Web. Sriwijaya Journal of Information Systems, 8(1), 131804.

Josi, A. (2017). PENERAPAN METODE PROTOTIPING DALAM PEMBANGUNAN WEBSITE DESA (STUDI KASUS DESA SUGIHAN KECAMATAN RAMBANG). Jurnal Teknologi Informasi MURA, 9(1).

Kusuma, D. H., Shodiq, M. N., Yusuf, D., \& Saadah, L. (2019). Si-Bidan: Sistem Informasi Kesehatan Ibu dan Anak. INTENSIF: Jurnal Ilmiah Penelitian dan Penerapan Teknologi Sistem Informasi, 3(1), 43-53.

Rosyidah, H. (2016). STRATEGI MENINGKATKAN KUALITAS PELAYANAN KESEHATAN MATERNAL STRATEGIES FOR IMPROVING THE QUALITY OF HEALTH CARE IN MATERNAL HEALTH. Jurnal Kebidanan, 5(1), 61-69.

Rusdiana, L. (2018). Dynamic Systems Development Method dalam Membangun Aplikasi Data Kependudukan Pada Kelurahan Rantau Pulut. Jurnal Transformatika, 16(1), 84-90.

Sofiyudin, A., \& Nugroho, R. A. (2017). Implementasi Cyber Village dalam Mewujudkan Masyarakat Melek Teknologi Informasi dan Komunikasi Berbasis Internet di Daerah Pegunungan (Studi Kasus di Desa Campurejo, Kecamatan Tretep, Kabupaten Temanggung, Jawa Tengah). Jurnal Wacana Publik, 1(3), $1-15$.

Sundari, J., \& Nainggolan, E. R. (2017). E-marketplace desa gerabah untuk pengrajin di desa bumi jaya serang banten. Journal Industrial Servicess, 3(1a).

Sutanta, E., \& Ashari, A. (2012). Pemanfaatan Database Kependudukan Terdistribusi pada Ragam Aplikasi Sistem Informasi di Pemerintah Kabupaten/Kota. Sisfotenika, 2(1), 11-20.

Utomo, F. S. B., Astuti, I. P., \& Setyawan, M. B. (2020). PERANCANGAN APLIKASI REKAM MEDIS BERBASIS ANDROID WEB SERVICE DENGAN MENGGUNAKAN RESTFUL API DI POLINDES DESA GOMBANG KECAMATAN SLAHUNG. KOMPUTEK, 4(2), 104-122. 